\title{
Integer to Physical Quantity Time Ratio Data Type
}

National Cancer Institute

\section{Source}

National Cancer Institute. Integer to Physical Quantity Time Ratio Data Type. NCI

Thesaurus. Code C95665.

A data type comprised of an integer divided by a physical quantity expressed in units of time. 